\title{
LOS GRANDES TEMAS DE CARLOS ITURRA EN LA DURACIÓN PROMEDIO DEL PRESENTE
}

\author{
Ewald Weitzdörfer \\ Hochschule Kempten \\ Kempten, Alemania \\ weitzd41@web.de
}

\section{TIEMPO, MUERTE, FILOSOFÍA, RELIGIÓN, HOMOSEXUALIDAD}

El hombre en el tiempo y delante de la muerte es, sin ningún género de duda, el problema más preocupante de la humanidad. Religiones y escuelas de filosofía han siempre tratado de facilitar alivios para mejor soportar la fatalidad de esta situación. Los escritores también. En el caso de Iturra son cuatro de sus libros de cuentos, que llevan ya en el título esta preocupación: Morir a tiempo (2014), Pretérito presente (2004), La paranoia de Dios (2010) y su libro más reciente, La duración promedio del presente (2016). Es interesante que en dos casos la idea del presente se ofrece en el título de manera sorpredente: En la gramática hay pretéritos de perfecto y de pluscuamperfecto, pero no de presente y en general no se habla de una duración promedio del presente. ¿Qué es entonces el presente? De los tres posibles aspectos del tiempo, el pasado, el presente y el futuro, el presente es el más problemático, porque en realidad no existe. Cuando escribo esta frase en el "presente", en verdad es ya parte del pasado y al escribir algo en el presente no se puede siempre conocer todas sus implicaciones.

En el relato "Un presente perdido" (La duración promedio del presente) Iturra relaciona el presente con el futuro y sostiene la hipótesis de que "el presente no se encuentra completo más que en el futuro", y que "la actualidad, el ahora, no son sino amagos del presente" y que "sólo en algún futuro por venir el presente será, en verdad y en plenitud el que fue" (23). Para dar prueba a esta hipótesis, el autor cita tres casos concretos, dos generalmente conocidos, el de Tutankamón y el de Jacqueline Kennedy y un imaginario, el de la abuela de Javier Santander, que desarrolla detalladamente a lo largo del cuento. En los tres casos, una verdad se descubre solo más tarde, en el futuro, y hace completo el presente.

En el cuento que da título al presente libro es difícil detectar una referencia lógica entre el presente y su duración promedio por un lado y el argumento de la historia por el otro. En realidad es un texto sicológico sobre la relación problemática entre padres e hijos: "todo hombre se pasa la vida en busca de su padre" (151). Lo que tienen en común 
es la idea de la imposibilidad: no hay medida de mesurar la duración del presente y no hay manera de solucionar el "misterio" (151) que representa un padre para su hijo. En el día de la muerte del padre, el hijo constatará "que lo había perdido para siempre antes de encontrarlo" (159).

El tema de la muerte es posiblemente uno de los más tratados por el escritor. Aunque solo uno de los libros de cuentos de Iturra lleva la idea de la muerte en el título (Morir a tiempo 2014), la muerte está presente en la mayoría de los otros libros, a veces de manera divertida y chistosa como en los cuentos del libro Para leer antes de tocar fondo (2007). En uno de los textos brevísimos un señor que se cayó de la azotea de un rascacielos ameniza su caída "leyendo divertidas historias, una de las cuales incluso le arrancó lágrimas de risa" (127). Otro ejemplo es la única frase del cuento "Caída libre": "Como el paracaídas no se iba a abrir, sacó su "Luger" y de un balazo se quedó en el cielo"(9). Sin embargo, en los otros libros la preocupación por la muerte es seria y se analiza en sus varios aspectos. En el libro La paranoia de dios (2010), por ejemplo, cinco cuentos tienen la muerte como tema, en forma de preocupación permanente y enfermiza del cincuentón Marcelo Rubio en el relato "Solo hay muerte mientras vives" (63-65), en la sublimación por la poesía en el caso de dos personas mortalmente enfermas ("Hadas lectoras" 113-115) o en forma de suicidio (malogrado) en el caso de dos amantes que quieren evitar la senectud ("Sin falta" 130). Como es de suponer, el tema de la muerte donde tiene su máxima presencia es en el ya mencionado libro Morir a tiempo. En esta obra casi todos los textos están relacionados con la muerte en sus varias facetas ( $c f r$. mi reseña en Hispanorama No. 152).

De los 23 cuentos de La duración promedio del tiempo, ocho tienen como tema la muerte o tratan de ella por lo menos marginalmente. El doctor Arrieta, un anciano de 85 años, que presencia el entierro de su prima, que había fallecido a los 100 años, es el protagonista del cuento "Sur y norte", la historia de una muerte, que se acepta como normal y natural. La muerte por accidente es la de la señora Rita Donoso en el cuento "Irse muy lejos". Pero el mensaje central de este texto no es la muerte; son más bien los sentimientos de mala consciencia de la narradora, su vecina, que no se ha ocupado de ella como debería haberlo hecho. La muerte por violencia o, mejor dicho, el asesinato es el tema en dos relatos, en el uno causada por motivos políticos ("El poeta fascista") y en el otro por motivos de vanidad ofendida ("El retrato de una dama"). Ideas filosóficas sobre el destino del hombre son las que dominan los dos relatos "Campanas doblando en Kioto" y "Una duda razonable”. En el primero, para mí uno de los mejores del libro, se llega a la conclusión de que lo que somos los hombres es "personas ciertamente sepultadas y olvidadas" (170), nada más. Una posición claramente nihilista. El segundo contiene reflexiones sobre el fenómeno de la muerte. Después de citar autoridades como Montaigne, Sócrates, Demócrito, Epicteto, Bergson y Schopenhauer, el autor llega a la conclusión de "que el fin de la filosofía es aprender a morir" (178). El señor Miguel Romo en el texto "Agrio crepuscular" por cierto todavía no ha aprendido su lección: Él representa el miedo de la criatura ante la muerte. El último de los relatos que tratan de la muerte es el cuento ya mencionado "Un presente perdido". En este caso, el tema de la muerte queda muy marginal, porque, como se ha dicho arriba, el problema central es el tiempo. 
Un cuento filosófico-ontológico es el texto "La estructura metálica". Aquí el autor entra en la discusión filosófica sobre la relación entre materia y espíritu basándose en autoridades como Demócrito, Giordano Bruno, Espinoza y, sobre todo, Schopenhauer, cuya tesis de que "lo que existe, cuanto vemos, es pura ilusón, producida por lo único real: la fuerza que está detrás de todo y que él llama voluntad” (188).

Como hemos visto, la filosofía trata de explicar el enigma de la existencia humana desde la antigüedad hasta nuestros días. Del mismo modo las religiones, desde tiempos remotos han tratado de dar sentido a la evidente absurdidad de la existencia humana (cfr. Albert Camus 1942), sobre todo con soluciones al máximo problema: la muerte.

De los libros de cuentos de Iturra, el que más se ocupa de este tema es La paranoia de dios (2010). Así, 13 de los 84 cuentos cortos del libro van en torno a la religión. La posición del autor frente a este tema puede resumirse así: anticlericalismo, ligera tendencia esotérica y la lucha interior contra un dios inexistente, muy bien desarrollado en el relato que da título al libro y resumida en estas palabras: "no hay Dios, pero me acosa" (226). (Para más detalles $c f r$. mi reseña en Alpha No. 32)

En el presente libro solo uno de los textos trata de este tema: "La mascota del paraíso". Es un texto blasfémico y burlón sobre la historia de la Biblia, en la que la serpiente seduce a Eva para que coma la manzana del árbol prohibido. Como se comprenderá, este texto es solo episódico y no entra en una discusión seria.

El motivo del anticlericalismo suele aparecer muchas veces en el contexto de la homosexualidad, que es otro de los grandes temas de Iturra.

Desde la publicación del libro Paisaje masculino en 1998, el tema de la homosexualidad ocupa un lugar importante en la producción cuentística del autor. Otro libro dedicado completamente al tema es El discípulo amado y otros paisajes masculinos de 2012.

Mientras en el primero el aspecto pornográfico queda todavía en el bajo fondo, asume una posición importante en el segundo ( $c f r$. mis reseñas en Hispanorama No. 93 y Alpha No. 40). En La duración promedio del tiempo el tema de la homosexualidad está presente en cuatro textos, a veces solo como un ingrediente más en una historia de otro tema, como p. ej., en el caso de "Agua", la historia de una catástrofe natural en el norte desértico de Chile. Originada por un temporal, una avalancha de barro pasa por el pueblo de Chañaral, llevandose todo lo que está en su camino. Entre las personas arrastradas por la avalancha está Gerardo, el novio del narrador. Desenlace feliz: el perro de Gerardo lleva al narrador al lugar donde está su amo y así Gerardo se salva.

En el texto "En un caserón azulino", Rafaelito, un retrasado mental de unos treinta años vive con su vieja madre. Un día, un tal Iván, prófugo de la justicia y buscado por la policía por triple homicidio, viene a la casa, introduce a Rafaelito a los placeres del amor homosexual y desaparece con él. En el cuento de carácter experimental a lo Cortázar "Lo que pudiste decirle a usted" se cuenta la historia del amor homosexual titubeante, y por fin no realizado del narrador Jorge y de Víctor, el hijo del interlocutor ausente, el señor Quezada, en los días de sus estudios universitarios. Los conflictos sociales que provoca la homosexualidad son el tema del relato "Castigar a un hijo". Es la historia de la familia de Francisco Javier quien, a los quince años se da cuenta de que "sentía atracción por sus amigos, no por sus amigas"(70). Cuando sus padres se enteran de esta situación "están 
disgustados, avergonzados, aterrados, frustrados" (70). Llevan al chico a varios psiquiatras y lo dejan en manos de un guía espiritual para quien "la homosexualidad es una severa anomalía moral,... al menos cuando se lleva a la práctica” (71). La convivencia en la familia se hace cada vez más crítica, hasta tal punto que un día el padre se levanta de la mesa, va a la ventana, y sobre el alféizar de la ventana antes de saltar dice: "Soy yo el que se larga.;Yo me largo! -y al momento de abalanzarse al vacío disparó hacia su hijo... una odiosa, virulenta, infame palabra, escupida con saña, una palabra- ¡Maricón! -que nunca había dirigido a Francisco Javier hasta entonces..." (76). El autor, como el lector, tienen sus dudas en cuanto a la verisimilitud de tal acción melodramática. Por eso, el autor recurre a una frase que dijo Chesterton acerca de la veracidad en la literatura: "la literatura tiene una obligación de la que la realidad carece por completo: debe ser verosímil" (76 s.), a lo que el autor añade: "y este caso no pertenece a la literatura, pertenece a la realidad y es infelizmente verídico" (77). Claro que la realidad no entra en literatura y por eso tenemos que tomar la declaración del autor como un recurso estilístico para promover el mensaje del cuento.

\section{CHILE, POLÍTICA, HISTORIA, SOCIEDAD}

El tema de Chile con su historia conflictiva del siglo XX está presente con mucho peso en el libro Crímen y perdón (2008). En uno de sus textos, el cuento más extenso de Iturra, "Caída en desgracia” (;37 páginas!), el autor, que se declara políticamente independiente en un artículo de La Tercera del 21 de noviembre de 2008, ofrece su versión del polémico taller literario de Mariana Callejas en los tiempos de la dictadura. Dos cuentos más de este libro tratan de la historia chilena contemporánea: "La familia dividida" y "La informante triangulada" ( $c f r$. mi reseña en Revista Chilena de Literatura No. 77).

Cuentos sobre la actualidad política, los problemas sociales en Chile y el paisaje chileno se encuentran también en los otros libros del autor. De los 23 cuentos de $L a$ duración promedio del presente seis tratan del tema chileno. En el cuento "Agua", ya mencionado arriba, la geografía del desierto al pie de los Andes en el norte chileno sirve de bajo fondo, o incluso más, para la historia de los dos amigos homosexuales. El tema de Chile en el texto "El retrato de una dama" se manifiesta en dos aspectos, el uno que tiene que ver con un fenómeno natural y el otro, con el problema social. Un temblor, o más bien terremoto, tan frecuente en Chile, interrumpe el trabajo de un pintor llamado a la casa de un señor muy rico, que tiene su vivienda de lujo en uno de los barrios menesterosos en el sur de Santiago para retratar a su señora. En un momento, los efectos del terremoto hacen que se descubre la pierna artificial de la modelo, que era "una compleja estructura metálica que por unos segundos se mostró como una especie de torre Eiffel invertida y con vaga forma de pierna" (83). El pintor "que cultivaba una variedad de hiperrealismo en ocasiones milagrosamente fotográfico" (79) se pone en seguida a pintar esa pierna artificial. Cuando se entera de lo que ha pasado, la señora "cayó en una especie de histeria y manda a su marido: “¡Mátalo, Heraldo, mátalo, que lo maten...”! Y en efecto el "mozo o guardaespaldas con aspecto de playboy gangsteril" (85) lo mata... . "Mapocho abajo aparecieron semanas después restos descompuestos de otro irrreconocible N.N." (85). 
El ambiente santiaguino entre gente de las capas sociales bajas visto por la perspectiva de un viejo solitario, don Miguel Romo, es el argumento del texto "Agrio crepuscular". Todo le molesta, sobre todo la arrogancia de los funcionarios, de manera que le parece preferible la muerte a esa vida: "se preguntó por qué diablos no le partía un rayo, por qué diablos no lo partía el corazón de una buena vez" (184). Un estudio social también es el cuento "Parientes lejanos". Es la historia de una familia numerosa que se traslada de un fundo en el sur a la ciudad de Temuco y que se pierde por la geografía chilena e incluso extranjera. Muchos años después, el narrador Jaime habla por teléfono con su prima $\mathrm{M}^{\mathrm{a}}$ Eugenia. En esta charla telefónica se descubre mucho de la vida social chilena.

Los dos otros cuentos de tema chileno "El poeta fascista" y "La Confederación se desplomó de repente" hablan del golpe y de la dictadura, pero de manera indirecta, con nombres imaginarios. El primero es la confesión tardía (50 años después de lo acontecido) de la persona que ejecutó al gran Braulio Rossi y a su hijo. Rossi fue el poeta e ideólogo de la dictadura, un personaje ambivalente, un gran poeta y un ideólogo sin compromiso. Su muerte había siempre sido un misterio no resuelto hasta esta confesión tardía. Los lectores chilenos tendrán sus ideas en cuanto a una interpretación histórica de este texto.

El segundo es una parodia genial sobre la situación política en un país imaginario con un régimen dictatorial llamado "La Confederación". Cuando, como dice el título, esta Confederación sin saber por qué se desplomó, "los héroes de la democracia salían de las cárceles y los colaboradores del finado Líder entraban” (123). El coronel Mussrá, "el autor intelectual y material del famoso atentado fallido contra la vida del Líder" es posiblemente uno de los más prominentes reclusos que salen en esta ocasión. Sale en silla de ruedas como víctima de la tortura de los confederados, pero convertido a sus ideas y lleno de desprecio para con sus antiguos compañeros demócratas. En el acto de la celebración del quinto aniversario "de lo que los necios demócratas llamaban ahora "La Liberación Nacional” (127), los demócratas quieren darle otra medalla -“una más grande que todas las anteriores, puesto que se trataba de celebrar cinco años, un quinquenio, ¡un lustro...!" (127). Cuando el presidente se acerca a él, Mussrá saca una pistola y lo mata gritando “¡Viva la Confederación!” (128). Mientras lo llevan a la prisión, Mussrá piensa en su futuro: "Todo lo que podía pasar ahora, aparte de volver a prisión... era que se detonase un alzamiento masivo y volviesen a sacarlo de prisión como un héroe, esta vez, de los confederados..." (128). El texto está lleno de ironía, de semitonos, un verdadero placer de lectura.

\section{LO FANTÁSTICO, ENIGMÁTICO, MARAVILLOSO, ONÍRICO}

Lo fantástico con todas sus variantes juega un papel muy importante en la obra cuentística de Carlos Iturra. Uno de sus libros está dedicado completamente a este tema (Cuentos fantásticos 2013) y otros, sobre todo los con un título a-normal como Preterito presente (2004) contienen numerosos cuentos de esta índole (cfr. mi artículo en Hispanorama No. 124). Esto es también el caso de La duración promedio del presente, que contiene tres relatos fantásticos. En el texto "Un sueño despierto", lo fantástico tiene que ver con lo onírico: Es la historia del tío Ricardo, cuya esposa y mascota habían muerto después 
de la quiebra de su fábrica de calcetines. Está tan triste que no quiere ir a celebrar las fiestas de Navidad en casa de su hermana. Prefiere ir a la cama. De repente, a las once de la noche, "como si llegara desde muy lejos, desde el fondo del sueño", lo despierta la campanilla de la puerta de entrada. Es su hermana Angélica con toda la familia, "con un gran pavo dorado en una fuente...con platos de tortas, de botellas de champán, vino y gaseosa...los pequeños con los brazos llenos de paquetes de regalo...el marido de Angélica con un gigantesco árbol de pascua..." (56). Entre realidad e irrealidad onírica se festeja una Navidad comme il faut con intercambio de regalos, con comida, bebida, charla, con mucho cariño... y, al final del cuento, Ricardo no se despierta por la mañana, triste y solo en su cama, no, el sueño se ha hecho realidad. Como los sueños, en el sentido no-metafórico de la palabra, no se pueden hacer realidad, esta "realidad" tiene que pertenecer a lo fantástico.

Lo fantástico en el texto "Hora de visitas" tiene que ver con los caprichos de la psiquis, que padece una anciana moribunda, que ha sufrido toda su vida de la desaparición de su primogénito Maxi. En su cama de la clínica habla con su hijo desaparecido y quiere comprender por qué se ha ido sin dejar noticias. En un momento, una de esas mujeres en blanco (que no se acuerda haber visto antes) entra y anuncia la visita de un señor que dice llamarse Maxi, Maximiliano Fernández. Y, en efecto, es su hijo, "que no ha cambiado una pizca, salvo un poco de barba crecida" (112). Los dos están llorando de alegría, una escena de inimaginable ternura: el hijo perdido ha vuelto. Ahora Maxi habla del motivo de su salida de la casa. Obviamente su padre había hecho insinuaciones de intención sexual cuando Maxi tenía trece años, lo que le hizo mucho daño y lo decidió a abandonar la casa. Luego, Maxi cuenta su vida en el "exilio" que termina con un accidente, que lo deja en estado de coma durante unos veinte años. Solo hace poco se ha despertado del coma. Le informaron en el hospital sobre la situación de su madre. Por eso vino a verla. Maxi promete a su madre volver el día después y llevarla consigo al departamento de ella, cuidarla, no apartarse más de ella... acompañarla hasta la muerte. Pero...el día después no viene nadie. ¿Ha sido una alucinación, un sueño o estará muerto Maxi y la ha visitado solamente su espíritu? No hay solución a este misterio. Un cuento muy emocionante entre realidad e irrealidad, magistralmente escrito.

"Pesadillas convergentes" es un cuento fantástico-onírico complejo, porque entrelaza las pesadillas de tres personas de manera admirable. Las tres personas son Domingo, el exmarido de María Isabel, María Isabel y su actual amante Rodolfo. Una noche, Domingo vive una situación escalofriante en une sueño, del que no le es posible despertar. Alguien entra en su dormitorio, se acerca a su cama con un hacha, que "precipitó sobre su cabeza como el rayo" (118). Las consecuencias de este sueño se ven en una realidad fantástica, en la que María Isabel sale de su casa, sube al auto sabiendo que "el trayecto...iba a costarle la vida" (119), va al departamento de su exmarido y lo mata con un hacha. Rodolfo, por fin, está en manos de una patrulla de policías sin saber por qué. Para él es como "un mal sueño" (120). Se le acusa como asesino del exmarido de su amante, quien, según información de la policía, había jurado matar a Domingo. Sus protestas no sirven para nada. Al final, "un hombre furibundo y todo de negro se asomaba hacia él... disponiéndose a imponerle la peor de las condenas, sin que a él le fuese posible más que repetir: ¡Noooo...!” (121). Lo fantástico, lo anormal en este cuento no reside 
primordialmente en las situaciones oníricas de las diversas pesadillas sino en el hecho de que forman una sola historia coherente.

Los temas de un autor dependen de su manera de ser y son tan variados como nosotros, los hombres, lo somos; el uno es alto, el otro bajo, el uno es rubio, el otro moreno, el uno es heterosexual, el otro homosexual... - De toda esa variedad de temas posibles se puede hacer buena o mala literatura según las calidades artísticas del autor. Carlos Iturra ha mostrado durante su ya bastante larga carrera de cuentista desde la publicación de su primer tomo de relatos Otros cuentos en 1987 hasta su más reciente en 2016 La duración promedio del presente que es un gran mago de estilo, de forma y de estructura, un aspecto de su obra, que sería material para otro estudio.

\section{BIBLIOGRAFÍA}

Iturra, Carlos. Otros cuentos. Santiago: Pehuén Editores, 1987.

Paisaje masculino. Santiago: Editorial Sudamericana, 1998.

Pretérito presente. Santiago: Catalonia, 2004.

Para leer antes de tocar fondo. Santiago: Catalonia, 2007.

Crimen y perdón. Santiago: Catalonia, 2008.

La paranoia de dios. Santiago: Catalonia, 2010.

El discípulo amado y otros paisajes masculinos. Santiago: Catalonia, 2012.

Cuentos fantásticos. Santiago: Catalonia, 2013.

Morir a tiempo. Santiago: Catalonia, 2014.

La duración promedio del presente. Santiago: Catalonia, 2016.

Camus, Albert. Le mythe de Sisyphe. Paris: Gallimard, 1942.

Weitzdörfer, Ewald. "Carlos Iturra, La paranoia de dios". ALPHA 32 (2011): 255-257.

229-230.

“Carlos Iturra, El discípulo amado y otros paisajes masculinos". ALPHA 40 (2015):

“Carlos Iturra, Paisaje masculino”. Hispanorama 93 (2001): 139.

"Situaciones ¿fantásticas? en Pretérito presente de Carlos Iturra". Hispanorama 124 (2009): 21-26.

“Carlos Iturra, Morir a tiempo”. Hispanorama 152 (2016): 131-132.

“Carlos Iturra, Crimen y perdón”. Revista Chilena de Literatura 77 (2010): 282-285. 